\title{
The Role of Surgeons' Colposcopic Experience in Ob- taining Adequate Samples by Large Loop Excision of the Transformation Zone in Women of Reproductive Age
}

\author{
Bedeutung der ärztlichen Erfahrung mit der Kolposkopie für die Entnahme \\ adäquater Proben mittels LLETZ bei Frauen im gebärfähigen Alter
}

Authors

Affiliations
R. Sparić ${ }^{1,2}$, A. Tinelli ${ }^{3,4}$, M. Guido ${ }^{5}$, R. Stefanović ${ }^{6}$, I. Babović ${ }^{1,2}$, V. Kesić ${ }^{1,2}$

The affiliations are listed at the end of the article.

Key words
LLETZ
specimen
conization
artifacts
colposcopic experience

Schlüsselwörter

- LLETZ

- Probe

- Konisation

- Artefakte

- kolposkopische Erfahrung

\section{received 14.2.2016 \\ revised 27.7.2016 \\ accepted 28.7.2016}

Bibliography

Dol http://dx.doi.org/

10.1055/s-0042-113773

Published online 9. 5.2016

Geburtsh Frauenheilk 2016; 76:

1339-1344 @ Georg Thieme

Verlag KG Stuttgart · New York

ISSN 0016-5751

\section{Correspondence}

Radmila Sparić, MD, MSc

Clinic for Gynecology

and Obstetrics

Clinical Centre of Serbia

Višegradska 26

11000 Belgrade

Serbia

radmila@rcub.bg.ac.rs

\section{Abstract}

$\nabla$

Introduction: There is insufficient reporting on the level of colposcopic training for the safe use of large loop excision of the transformation zone. The aim of this study was to perform a quality assessment of large loop excision of the transformation zone in women of reproductive age by evaluating the surgeons' colposcopic experience.

Materials and Methods: A retrospective cohort study was performed on diagnostic or therapeutic large loop excision of the transformation zone. The following variables were analyzed: age, parity, indications for surgery, level of surgeon's colposcopic experience, definitive histological diagnosis, margin involvement, and the presence and type of artifacts interfering with the pathological interpretation. Patients were divided into three groups: group A - 75 patients treated by junior colposcopists; group B - 74 patients treated by experienced colposcopists, and group C - 117 patients treated by expert colposcopists.

Results: Regarding the presence and diagnostic significance of the artifacts the groups were significantly different. Inadequate samples were the least frequent in group C. Artifacts precluding histological diagnosis were the most common in group A. The margins were predominantly inconclusive in group $A$.

Conclusions: A high rate of artifacts is a disadvantage of the large loop excision of the transformation zone performed by surgeons less skilled for colposcopy. Although large loop excision of the transformation zone is considered to be a minor surgery, skills in colposcopy are an essential prerequisite for optimal results.

\section{Zusammenfassung \\ $\nabla$}

Einleitung: Es gibt nur wenige Berichte über die Bedeutung ausreichender Erfahrung in der Kolposkopie für die Sicherheit bei großflächigen Resektionen der Transformationszone. Ziel der Studie war es, die Qualität bei großflächigen Schlingenexzisionen der Transformationszone (LLETZ) zu bewerten, die bei Frauen im gebärfähigen Alter durchgeführt wurden. Es wurde untersucht, inwieweit die Qualität des Eingriffs mit der kolposkopischen Erfahrung des Chirurgen korrelierte. Material und Methoden: Es wurde eine retrospektive Kohortenstudie bei Patientinnen durchgeführt, die einer diagnostischen oder therapeutischen LLETZ zugeführt wurden. Dabei wurden die folgenden Variablen untersucht: Alter, Anzahl vorhergehender Geburten, Indikationen zur chirurgischen Therapie, kolposkopische Erfahrung des Chirurgen, endgültige histologische Diagnose, Tumorfreiheit der Resektionsränder sowie Anwesenheit von und Art der Artefakte, die eine pathologische Diagnose nur einschränkt erlaubten. Die Patientinnen wurden in 3 Gruppen eingeteilt: Gruppe A bestand aus 75 Patientinnen, die von Assistenzärzten untersucht wurden, die noch nicht viel Erfahrung mit der Kolposkopie gesammelt hatten; Gruppe B bestand aus 74 Patientinnen, die von Ärzten mit mehrjähriger Erfahrung in der Kolposkopie behandelt wurden; Gruppe C bestand aus 117 Patientinnen, die von Fachärzten mit langjähriger Erfahrung in der Kolposkopie behandelt wurden.

Ergebnisse: Die Gruppen unterschieden sich signifikant im Hinblick auf die Anwesenheit von $\mathrm{Ar}$ tefakten und der diagnostischen Wertigkeit der entnommenen Proben. In der Gruppe C war die Anzahl inadäquater Proben am geringsten. Artefakte, die eine histologische Diagnose verhinderten, kamen am häufigsten in der Gruppe A vor. Bei den Frauen der Gruppe A waren die Resektionsränder meist nicht eindeutig. 
Schlussfolgerung: Die höchste Artefaktrate bei der LLETZ fand sich in der Gruppe von Ärzten mit geringer Erfahrung in der Kolposkopie. Obwohl die großflächige Schlingenresektion der Transformationszone als kleiner Eingriff gewertet wird, ist eine langjährige Erfahrung in der Kolposkopie eine wesentliche Voraussetzung, um optimale Ergebnisse zu erzielen.

\section{Introduction \\ $\nabla$}

Large loop excision of the transformation zone (LLETZ) is a commonly used technique for managing women with pathological changes on the uterine cervix, which has gained worldwide acceptance due to its numerous advantages [1-4]. Unlike ablative methods, LLETZ allows histological examination of the excised tissue [1-4].

However, LLETZ causes thermal damage of specimens [5], due to the use of electricity, which simultaneously cuts and coagulates the tissue [6]. Thermal artifacts interfere with the pathological analysis [7]. Furthermore, there is the problem of multiple excisions, which are necessary to manage large ectocervical lesions. This causes specimen fragmentation that hampers assessment of the margins [8]. All those factors may have a negative impact on the further management of women in reproductive age, who need an accurate and minimally invasive treatment for their future fertility.

LLETZ effectiveness and cure rates, adverse effects, complications, both short-term and long-term clinical outcomes and its influence on fertility have been widely investigated [1]. However, the risk factors for obtaining inadequate specimen and subsequent difficulties in histological interpretation, particularly in terms of surgeons' skills and experience in colposcopy, are yet to be identified $[3,9]$.

The aim of this study was to perform the quality assessment of LLETZ procedure in women of reproductive age, by investigating the colposcopic experience of the surgeons, and its influence on the presence, diagnostic significance and type of artifacts and their influence on histological interpretation and specimen adequacy.

\section{Materials and Methods}

$\nabla$

\section{Study design}

A retrospective cohort study was performed in a university-affiliated hospital over a four-year period, between January 2010 and December 2013. The Institutional Review Board approved the study.

Our colposcopy service provides consultations for patients that are referred for abnormal Pap smears and/or colposcopies. Women suspected of having cervical dysplasia or HPV lesions following a Pap test and a colposcopy are either referred to a biopsy or a LLETZ procedure, based on the judgment of the attending colposcopist and the patient's wishes. In addition, our colposcopy clinic provides consultative service for patients included in the IVF procedures covered by the national health care system, as well as for the patients from national transplantation clinics. In such patients, a follow-up is not acceptable and immediate LLETZ treatment of any abnormalities is requested. LLETZ indications further included discrepancies between cytology, colposcopy and biopsy results, persistent ( $>2$ years) low-grade abnormalities, according to the national protocol and patients' request for maximum oncological safety. Some of the patients were treated with LLETZ procedure upon their request, as some women were not willing to comply with the other treatment modalities or/and follow-up visits. In our culture, patients prefer LLETZ conization to other treatments, as they traditionally consider this approach to be oncologically safer. This is probably due to the absence of well-organized screening programs and a relatively high mortality of invasive cervical cancer in our country. Thus, some of the patients in our study had been submitted directly to LLETZ instead of to diagnostic biopsy. In such patients, the indications for the LLETZ treatment included abnormal colposcopy and/or cytology.

\section{LLETZ excision procedure}

All patients gave informed consent for the LLETZ. All the procedures were performed under general anesthesia using Valley Lab Force Triad Electrosurgical Unit (Covidien Ltd, Dublin, Ireland). Loop electrodes were chosen by surgeons' preference, either $20 \times 15 \mathrm{~mm}$ or $10 \times 10 \mathrm{~mm}$ curvilinear loop and ball $3 \mathrm{~mm}$ or $5 \mathrm{~mm}$ in diameter. Unit was calibrated from 35 watt to 45 watt.

\section{Selection of patients}

The exclusion criteria were pregnancy, age over 45 , menopausal status, invasive or micro invasive carcinoma of the cervix, adenocarcinoma in situ, and re-treatment for positive margins after previous surgery, and missing data relevant for the study. The following data from the pathological records were taken: age, parity, and previous cervix treatment, indication for surgery, surgeon's level of colposcopic experience, definitive histological diagnosis and margin involvement, specimen fragmentation, presence and type of artifacts and their interference with the histological interpretation. The LLETZ indications were divided into three categories: abnormal Pap smear, colposcopy, or histology (in cases of prior biopsy). According to biopsy results, histological diagnoses were divided into subcategories: condyloma, CIN 1, CIN 2 and CIN 3. Surgeons were grouped according to their experience in colposcopy into three categories: expert, experienced and junior colposcopists. The descriptors of the groups by experience are presented in Table 1. A total of 266 patients were divided into three groups: group A - 75 patients operated by juniors; group $\mathrm{B}-74$ patients operated by experienced, and group $\mathrm{C}$ - 117 patients operated by expert colposcopists.

\section{Histopathological procedure}

The specimens were collected in plastic boxes, separately fixed, labeled and microscopically evaluated. Pathologists proficient in gynecological pathology, who provide pathological reviewing for national referral service, assessed histological diagnosis and margin involvement. They were not blinded to the surgery indications. Margin status was reported for all the pieces in cases of specimen fragmentation. The artifacts determined by the pathologist were grouped according to their influence on histological diagnosis as absent, present but not interfering with the histological diagnosis and present as well as interfering with the histolog- 
ical diagnosis. The types of artifacts assessed were categorized as thermal damage, fragmentation and multiple artifacts. Mechanical damage of the specimen was not described as an isolated artifact in any of the cases.

\section{Statistical analysis}

The data were analyzed using SPSS 17.0 (Chicago, USA), with a significance level set at 0.05 . For continuous variables, the differences between groups were compared by 1 -way analysis of variance (ANOVA). ANOVA was performed with a Brown-Forsythe adjustment for heteroscedasticity and with post-hoc Tukey or Dunnett's T3 procedure for multiple comparisons. The Pearson $\mathrm{X}^{2}$ and likelihood ratio $\mathrm{X}^{2}$ as appropriate were used for proportions.

\section{Results}

\section{Characteristics of investigated patients}

There were no differences between the patients in the defined groups analyzing the age, age at menarche, number of previous abortions and deliveries, previous cervix treatment and LLETZ indications. The majority of the patients, 177 (66.54\%) were nulliparous. Patients' demographic and clinical data are presented in - Table 2.

\section{Characteristics of assessed specimens}

There was a significant difference among the groups with respect to specimen adequacy for pathological assessment. Overall, 238 specimens were adequate for pathological assessment, most frequently in group C (94.87\%). Out of 28 inadequate specimens, $53.57 \%$ were in group A. Groups exhibited differences in terms of both the presence and the diagnostic significance of the artifacts. Artifacts were most commonly present in group A, and absent in group C. Diagnostically significant artifacts, interfering with the histological diagnosis, were present in 28 (10.53\%) of the cases, with significant differences among the groups. Artifacts precluding histological diagnosis were most common in group A (53.57\% of the cases). There was no difference among the groups regarding the type of artifacts. The most common ar-
Table 1 The descriptors of the groups by experience.

\begin{tabular}{|c|c|}
\hline Category & Definition \\
\hline $\begin{array}{l}\text { Expert } \\
\text { colposcopist }\end{array}$ & $\begin{array}{l}\text { Gynecologists certified in colposcopy, with more than } \\
20 \text { years in experience, performing more than } 30 \text { colpos- } \\
\text { copies per week and performing colposcopy consulta- } \\
\text { tions for other groups, also involved in both lectures and } \\
\text { practical education at the National School of Colposcopy }\end{array}$ \\
\hline $\begin{array}{l}\text { Experienced } \\
\text { colposcopist }\end{array}$ & $\begin{array}{l}\text { Gynecologists certified in colposcopy, with more than } \\
10 \text { and less than } 20 \text { years of experience, performing } 15 \text { to } \\
30 \text { colposcopies per week, who are involved in practical } \\
\text { education at the National School of Colposcopy }\end{array}$ \\
\hline $\begin{array}{l}\text { Junior } \\
\text { colposcopist }\end{array}$ & $\begin{array}{l}\text { Gynecologists certified in colposcopy, with less than } \\
10 \text { years of experience, performing up to } 15 \text { colposcopies } \\
\text { per week, who are not involved in any kind of education } \\
\text { at the National School of Colposcopy }\end{array}$ \\
\hline
\end{tabular}

tifacts were thermal (11.28\%), followed by multiple artifacts (9.40\%), while fragmentation $(4.14 \%)$ was the least present. Multiple artifacts were most common in group A. Of the 266 specimens, 176 (66.17\%) were obtained in one piece, without differences between the groups ( $p=0.160)$. However, it is noteworthy that the number of fragments was the highest in group A (data not shown). The data about the quality and adequacy of the specimen are listed in 0 Table 3.

\section{Histology and margin status of specimens}

There was no difference among the groups regarding definitive histological diagnosis, although it was close to a statistical significance ( $p=0.088$ ). In terms of margin status, there was a significant difference among the groups. Endocervical and ectocervical margins were most frequently inconclusive in group A. Out of 27 specimens with both margins inconclusive, 55.56\% were in the group A. The incidence of positive ectocervical margin throughout the study was $8.27 \%$, with the lowest frequency in group $\mathrm{C}$ (7 of 117 , i.e. $5.98 \%$ ). Out of 184 specimens with both margins negative, $45.11 \%$ were in group C, $30.43 \%$ were in group B and $25.46 \%$ were in group A. Definitive histological diagnoses and margin status of the specimens are listed in Table 4.

Table 2 Patients' demographic and clinical data.

\begin{tabular}{|c|c|c|c|c|c|}
\hline Data & Total $(n=266)$ & Group A $(n=75)$ & Group B $(n=74)$ & Group C $(n=117)$ & $\mathbf{p}$ \\
\hline \multicolumn{6}{|c|}{ Patients' characteristic (mean \pm SD) } \\
\hline Age (years) & $31.58 \pm 5.66$ & $31.81 \pm 5.79$ & $31.65 \pm 6.32$ & $31.38 \pm 5.16$ & $0.871^{\mathrm{a}}$ \\
\hline Menarche (years) & $13.09 \pm 1.39$ & $13.19 \pm 1.34$ & $13.02 \pm 1.35$ & $13.07 \pm 1.45$ & $0.796^{\mathrm{b}}$ \\
\hline Number of abortions & $0.31 \pm 0.66$ & $0.29 \pm 0.59$ & $0.46 \pm 0.80$ & $0.24 \pm 0.60$ & $0.081^{\mathrm{a}}$ \\
\hline Number of deliveries & $0.46 \pm 0.81$ & $0.50 \pm 0.84$ & $0.46 \pm 0.91$ & $0.44 \pm 0.73$ & $0.893^{b}$ \\
\hline \multicolumn{6}{|c|}{ Clinical data n (\%) } \\
\hline \multicolumn{6}{|c|}{ Previous treatment of the cervix } \\
\hline None & $247(92.86)$ & $72(96.00)$ & 70 (94.59) & $105(89.74)$ & $0.451^{c}$ \\
\hline Destruction & $3(1.13)$ & $0(-)$ & $1(1.35)$ & $2(1.71)$ & \\
\hline - Excision & $16(6.02)$ & $3(4.00)$ & $3(4.05)$ & $10(8.55)$ & \\
\hline \multicolumn{6}{|l|}{ Indication for LLETZ } \\
\hline Abnormal Pap & $135(50.75)$ & $41(54.67)$ & $38(51.35)$ & $56(47.86)$ & $0.287^{d}$ \\
\hline - Colposcopy & $46(17.29)$ & $8(10.67)$ & $17(22.97)$ & $21(17.95)$ & \\
\hline Histology & $85(31.95)$ & $26(34.67)$ & $19(25.68)$ & 40 (34.19) & \\
\hline
\end{tabular}

a ANOVA was performed with a Brown-Forsythe adjustment for heteroscedasticity and with post-hoc Tukey or Dunnett's T3 procedure for multiple comparisons of unequal variances; ' ${ }^{\circ}$ Between-groups comparison with equal variance was performed by 1 -way ANOVA; ' Likelihood ratio $\chi^{2}$; d Pearson's $\chi^{2}$ test. 
Table 3 Specimen adequacy and quality.

\begin{tabular}{|c|c|c|c|c|c|}
\hline Parameter & $\begin{array}{l}\text { Total } \\
n=266 \text { (\%) }\end{array}$ & $\begin{array}{l}\text { Group A } \\
n=75 \text { (\%) }\end{array}$ & $\begin{array}{l}\text { Group B } \\
n=74(\%)\end{array}$ & $\begin{array}{l}\text { Group C } \\
n=117 \text { (\%) }\end{array}$ & $\mathbf{p}$ \\
\hline \multicolumn{6}{|l|}{ Specimen adequacy } \\
\hline Adequate & $238(89.47)$ & $60(80.00)$ & $67(90.54)$ & $111(94.87)$ & $0.004^{\mathrm{a}}$ \\
\hline Inadequate & $28(10.53)$ & $15(20.00)$ & $7(9.46)$ & $6(5.13)$ & \\
\hline \multicolumn{6}{|l|}{ Presence of artifacts } \\
\hline Absent & $200(75.19)$ & $52(69.33)$ & $51(68.92)$ & $97(82.91)$ & $0.036^{\mathrm{a}}$ \\
\hline Present & $66(24.81)$ & $23(30.67)$ & $23(31.08)$ & $20(17.09)$ & \\
\hline \multicolumn{6}{|l|}{ Diagnostic significance of artifacts } \\
\hline Absent & $200(75.19)$ & $52(69.33)$ & $51(68.92)$ & $97(82.91)$ & $0.004^{\mathrm{a}}$ \\
\hline Present and diagnostically not significant & $38(14.29)$ & $8(10.67)$ & $16(21.62)$ & $14(11.97)$ & \\
\hline Present and diagnostically significant & $28(10.53)$ & $15(20.00)$ & $7(9.46)$ & $6(5.13)$ & \\
\hline \multicolumn{6}{|l|}{ Type of artifacts } \\
\hline Absent & $200(75.19)$ & $53(70.67)$ & $51(68.92)$ & $96(82.05)$ & $0.080^{\mathrm{b}}$ \\
\hline Thermal damage & $30(11.28)$ & $6(8.00)$ & $13(17.57)$ & $11(9.40)$ & \\
\hline Fragmentation & $11(4.14)$ & $5(6.67)$ & $4(5.41)$ & $2(1.71)$ & \\
\hline Multiple artifacts & $25(9.40)$ & $11(14.67)$ & $6(8.11)$ & $8(6.84)$ & \\
\hline \multicolumn{6}{|l|}{ Specimen fragmentation } \\
\hline One piece & $176(66.17)$ & $43(57.33)$ & $51(68.92)$ & $82(70.09)$ & $0.160^{\mathrm{a}}$ \\
\hline Two and more pieces & $90(33.83)$ & $32(42.67)$ & $23(31.08)$ & $35(29.91)$ & \\
\hline
\end{tabular}

a Pearson's $x^{2}$ test; ${ }^{b}$ Likelihood ratio $x^{2}$.

Table 4 Histological diagnoses and margin status of the specimen.

\begin{tabular}{|c|c|c|c|c|c|}
\hline Parameter & $\begin{array}{l}\text { Total } \\
n=266 \text { (\%) }\end{array}$ & $\begin{array}{l}\text { Group A } \\
n=75 \text { (\%) }\end{array}$ & $\begin{array}{l}\text { Group B } \\
n=74(\%)\end{array}$ & $\begin{array}{l}\text { Group C } \\
n=117 \text { (\%) }\end{array}$ & $\mathbf{p}$ \\
\hline \multicolumn{6}{|l|}{ Histological diagnosis } \\
\hline Normal & $80(30.08)$ & $19(25.33)$ & $25(33.78)$ & $36(30.77)$ & $0.088^{\mathrm{a}}$ \\
\hline Condyloma & $34(12.78)$ & $12(16.00)$ & $14(18.92)$ & $8(6.84)$ & \\
\hline CIN 1 & $30(11.28)$ & $8(10.67)$ & $10(13.51)$ & $12(10.26)$ & \\
\hline CIN 2 & $27(10.15)$ & $6(8.00)$ & $9(12.16)$ & $12(10.26)$ & \\
\hline CIN 3 & $95(35.71)$ & $30(40.00)$ & $16(21.62)$ & $49(41.88)$ & \\
\hline \multicolumn{6}{|l|}{ Margin status } \\
\hline \multicolumn{6}{|l|}{ Ectocervical margin } \\
\hline - Negative & $217(81.58)$ & $53(70.67)$ & $59(79.73)$ & $105(89.74)$ & $0.005^{\mathrm{a}}$ \\
\hline Positive & $22(8.27)$ & $7(9.33)$ & $8(10.81)$ & $7(5.98)$ & \\
\hline Inconclusive & $27(10.15)$ & $15(20.00)$ & $7(9.46)$ & $5(4.27)$ & \\
\hline \multicolumn{6}{|l|}{ Endocervical margin } \\
\hline Negative & $188(70.68)$ & $47(62.67)$ & $57(77.03)$ & $84(71.79)$ & $0.011^{\mathrm{a}}$ \\
\hline Positive & $50(18.80)$ & $13(17.33)$ & $10(13.51)$ & $27(23.08)$ & \\
\hline Inconclusive & $28(10.53)$ & $15(20.00)$ & $7(9.46)$ & $6(5.13)$ & \\
\hline \multicolumn{6}{|l|}{ Margin condition (both margins) } \\
\hline Both margins negative & $184(69.17)$ & $45(60.00)$ & $56(75.68)$ & $83(70.94)$ & $0.007^{\mathrm{b}}$ \\
\hline Both margins positive & $18(6.77)$ & $5(6.67)$ & $7(9.46)$ & $6(5.13)$ & \\
\hline - Both margins inconclusive & $27(10.15)$ & $15(20.00)$ & $7(9.46)$ & $5(4.27)$ & \\
\hline One margin positive & $36(13.53)$ & $10(13.33)$ & $4(5.41)$ & $22(18.80)$ & \\
\hline - One margin inconclusive & $1(0.38)$ & $0(-)$ & $0(-)$ & $1(0.85)$ & \\
\hline
\end{tabular}

a Pearson's $X^{2}$ test; ${ }^{b}$ Likelihood ratio $X^{2}$.

\section{Discussion}

$\nabla$

Adequate management of cervical dysplasia is an important step in cervical cancer prevention [10]. The cure rates following LLETZ have been broadly investigated with respect to patients' age, parity, size and grade of lesion, cone size and volume, as well as the use of various LLETZ technique modifications [2,4,11-13]. However, data on surgeons' colposcopic experience and its influence on specimen quality, the presence and diagnostic significance of the artifacts have been inadequately studied. The difficulties in margin assessment due to the presence of artifacts are also de- scribed, particularly from the pathologists' point of view [8]. Surgical textbooks and publications often underline the significant influence of surgical experience on surgery results [6,14]. Nevertheless, surgical experience is not the only determining factor of LLETZ specimen quality. The issue of sufficient colposcopic experience to verify one's certification for the LLETZ has not been evaluated enough. LLETZ is performed by surgeons experienced in both oncology and colposcopy, as well as by general practitioners and nurses, sometimes with very limited experience in colposcopy. This is due to the belief that LLETZ has an easier learning curve in comparison to the other conization techniques [2]. 
Inadequate specimens increase the treatment failure rate; they impair the patient's psychological well-being and cause additional costs. Besides, publications about possible adverse perinatal outcomes after LLETZ pose a serious question regarding its application in women of reproductive age by surgeons inexperienced in colposcopy $[15,16]$. Thus, inadequate treatment of cervical dysplasia in women of the reproductive age influences both the risk of future cervical cancer development and perinatal complications [2].

Adequate histological interpretation of the LLETZ specimen requires complete assessment of the margins. Literature data suggest that several patient and surgeon characteristics may influence sample adequacy [3]. Patient related factors include habitus, relaxation and vaginal compliance, age, parity, indication for the surgery and morphology and grade of the disease. Surgeon related factors include experience and colposcopic impression lesion morphology, loop size shape and speed of passage through the tissue, current settings and colposcopic interposition [7,17]. Our study groups did not differ in relation to demographic and clinical data. We documented a lower incidence of artifacts with the higher the level of colposcopic expertise. Furthermore, colposcopy experience significantly influenced margin status, as well as the presence and diagnostic significance of the artifacts. Both inadequate specimens and artifacts were the most frequent in group A. Artifacts precluding margin assessment were the most frequent in group A. The type of artifacts was not influenced by colposcopy experience, although multiple artifacts were most frequent in group A. LLETZ procedure is associated with thermal artifacts at all the margins, which could limit the adequacy and quality of the specimen and preclude margin assessment $[7,8,13]$. The published incidence rates are up to $48 \%$ [18]. Wright et al. [19] found the range of thickness of the coagulated zone in LLETZ cones to be 0.150 to $0.830 \mathrm{~mm}$, with a mean of $0.396 \mathrm{~mm}$. Baggish et al. [20] found the depth of coagulation at the ectocervical margin to be $0.187 \mathrm{~mm}$ and at the endocervical margin $0.295 \mathrm{~mm}$. Nevertheless, the presence of thermal injury influences the interpretation of the margins only in specimens with no healthy tissue between the dysplastic and coagulated area. The frequency of thermal artifacts in our study corresponds to the previously published results, and its incidence is confirmed to be surgeon dependent [21,22]. Messing et al. [8] evaluated the specimens obtained by residents and found that $26.09 \%$ of them had severe thermal artifacts precluding the evaluation for both the grade of dysplasia and the margins. Thermal artifacts are determined by the loop size, speed of cutting, electrical energy and tissue conductivity $[3,8,17]$. In cases of repeated excisions, artifacts are present on all sides of the specimens, except on the ectocervical surface [8]. Incidence of thermal artifacts and depth of the coagulation zone could be reduced with appropriate loop size, adequate power settings and improvement of surgeons' colposcopic skills. All the above-mentioned factors, except tissue conductivity are surgeon dependent and influenced by experience [8].

Specimen fragmentation mainly results from poor surgical technique and it increases diagnostic uncertainty [8]. In cases of large ectocervical lesions, multiple excisions are inevitable as loop size limits the size of the cone, which is not true for cold knife or laser conization. Based on the recommendations of the National Health Service Cervical Screening Programme from the United Kingdom, at least $80 \%$ of the LLETZ procedures should result in single piece specimen, which is a marker of good practice [23]. Still, the rate of single fragment LLETZ cones in literature ranges from 49 to $92 \%[2,6]$. The trainee status in colposcopy was previously established to be a substantial risk factor for specimen fragmentation [3]. Cure rates are also lower in cases of lesions treated with multiple LLETZ excisions. Papoutsis et al. [2,24] found that increased incidence of multiple excisions, even when performed by experienced colposcopists, did not result in a higher rate of negative margins. Bharathan et al. [3] documented an influence of specimen fragmentation on both the margin involvement and inconclusive margins, while trainee status was related to specimen fragmentation, which was present in $25 \%$ of patients. Despite failing to prove that colposcopy experience influenced fragmentation, we found that the rate of fragmented specimens was inversely related to colposcopic experience.

The incidence of positive ectocervical margins may be reduced by performing the excision under colposcopic guidance. However, this cannot reduce the incidence of positive ectocervical margins, if a surgeon is not properly trained in colposcopy. An incidence of positive margins of $39.96 \%$ was reported in a study where the majority of LLETZ procedures were performed by residents [8]. We documented the lowest incidence of negative margins in group A. Miroshnichenko et al. [25] found that the incidence of positive margins was $38 \%$ in LLETZ procedures performed by experienced gynecologic oncologists. Out of 96 specimens, $85 \%$ had entirely interpretable margins. Urlich et al. [9] established that certification in colposcopy influences the rate of positive margins in a study including 334 CKCs and 25 LLETZ. None of the specimens obtained by gynecologists certified in colposcopy had uncertain margins, so they concluded that certification and experience in colposcopy improves the rate of free margins, which corresponds to our results. Apart from colposcopic experience, the lowest rate of inconclusive endocervical margins in group $\mathrm{C}$ can be explained by the lowest rate of fragmented samples in this group. Although we failed to prove a difference in the incidence of specimen fragmentation among the groups, this does not necessarily mean that fragmentation has no clinical significance on the occurrence of inconclusive margins. Montz et al. [7] documented a lesser depth of coagulation artifacts at the endocervix in cases of single specimens as compared to fragmented ones. Boardman et al. [26] found an incidence of inconclusive margins of $27 \%$ in women operated by physicians in training, which is similar with the incidence of inconclusive margins in group $\mathrm{A}$.

The status of margins determines both the postoperative followup and management. In cases of inconclusive margins, the lesion may be both entirely excised and not excised. Such patients require further close follow-up, diagnostics or even repeated treatment, which increases healthcare costs, and physicians' anxiety, and disrupts patients' quality of life. In women of reproductive age, this outcome could postpone pregnancy. Thus, for women desiring pregnancy, we suggest that expert colposcopists should perform LLETZ, because LLETZ could also lead to unfavorable perinatal outcomes $[15,16]$.

This study has several drawbacks. The analyzed data were generated from pathological reports, which may limit their quality. Nevertheless, a retrospective study design allowed us to study the LLETZ practice without bias, by not allowing surgeons to adjust their technique and patient selection according to the nature of investigation. This eliminates the Hawthorne effect, and, therefore, we believe that the obtained results could be clinically useful to those who treat women of reproductive age with cervical dysplasia.

The high rate of cone specimens free of disease is another limitation of our study, which is influenced by the indications for the 
procedure. Nevertheless in our setting, regardless of the histological specimen diagnosis, pathologists in their reports describe as part of routine practice the quality of the specimen, margin status and presence of artifacts, as well as the number of fragments. This is customary both in cases with cervical dysplasia and where it is absent. As the aim of the study was to evaluate the quality of specimens, in terms of the presence of artifacts that could possibly interfere with pathological assessment, the authors believe that the surgical technique was not influenced by the specimen histology, thus enabling us to compare the performance of various surgeons in all the cases included.

Our investigation is lacking data on managing patients with positive and inconclusive margins, as well as follow-up data. The results are not applicable to all women, given that we have only studied women of reproductive age treated with LLETZ. Although our results represent the experience of one teaching hospital, we must underline that they also represent the practice of 48 surgeons with different levels of colposcopic experience. In the hands of surgeons with less experience in colposcopy, as we demonstrated, LLETZ is compromised by the following disadvantages: a high frequency of artifacts and inconclusive margins.

\section{Conclusions}

We believe that our study will provide valuable information for the education of the medical personnel managing cervical dysplasia by LLETZ. Although LLETZ is considered a minor surgery, this study indicates that skills in colposcopy are an essential prerequisite for optimal results.

\section{Conflict of Interest}

$\nabla$

The authors declare that they have no competing interests.

\section{Affiliations}

${ }^{1}$ Clinic for Gynecology and Obstetrics, Clinical Centre of Serbia, Belgrade, Serbia

2 School of Medicine, University of Belgrade, Belgrade, Serbia

${ }^{3}$ International Translational Medicine and Biomodeling Research Group Department of Applied Mathematics, Moscow Institute of Physics and Technology (State University), Moscow, Russia

${ }^{4}$ Division of Experimental Endoscopic Surgery, Imaging, Technology and Minimally Invasive Therapy of Centre for Interdisciplinary Research Applied to Medicine Department of Obstetrics and Gynecology Vito Fazzi Hospital, Lecce, Italy

${ }^{5}$ Laboratory of Hygiene, Department of Biological and Environmental

Sciences and Technologies, Faculty of Sciences, University of Salento, Lecce, Italy

${ }^{6}$ Department for Histopathology, Clinical Center of Serbia, Belgrade, Serbia

\section{References}

1 Martin-Hirsch PP, Paraskevaidis E, Bryant A et al. Surgery for cervical intraepithelial neoplasia. Cochrane Database Syst Rev 2013; (12): CD001318

2 Papoutsis D, Rodolakis A, Mesogitis S et al. Appropriate cone dimension to achieve negative excision margins after large loop excision of transformation zone in the uterine cervix for cervical intraepithelial neoplasia. Gynecol Obstet Invest 2013; 75: 163-168

3 Bharathan R, Sagoo B, Subramaniam A et al. LLETZ specimen fragmentation: impact on diagnosis, outcome and implications for training. J Obstet Gynaecol Ind 2013; 63: 332-336

4 Leimbacher B, Samartzis N, Imesch P et al. Inpatient and outpatient loop electrosurgery excision procedure for cervical intraepithelial neoplasia: a retrospective analysis. Arch Gynecol Obstet 2012; 285: 14411445
5 Garcia Ramos AM, Garcia Ramos ES, Dos Reis HL et al. Quality evaluation of cone biopsy specimens obtained by large loop excision of the transformation zone. J Clin Med Res 2015; 7: 220-224

6 Bittencourt DD, Zanine RM, Sebastiao AM et al. Number of fragments, margin status and thermal artifacts of conized specimens from LLETZ surgery to treat cervical intraepithelial neoplasia. Sao Paolo Med J 2012; 130: 92-96

7 Montz FJ, Holschneider CH, Thompson LD. Large-loop excision of the transformation zone: effect on the pathologic interpretation of resection margins. Obstet Gynecol 1993; 81: 976-982

8 Messing MJ, Otken L, King LA et al. Large loop excision of the transformation zone (LLETZ): a pathologic evaluation. Gynecol Oncol 1994; 52: 207-211

9 Ulrich D, Tamussino K, Petru E et al. Conization of the uterine cervix; does the level of gynecologist's training predict margin status? Int J Gynecol Pathol 2012; 31: 382-386

10 Duesing N, Schwarz J, Choschzick M et al. Assessment of cervical intraepithelial neoplasia (CIN) with colposcopic biopsy and efficacy of loop electrosurgical excision procedure (LEEP). Arch Gynecol Obstet 2012; 286: 1549-1554

11 Papoutsis D, Rodolakis A, Antonakou A et al. Cervical cone measurements and residual disease in LLETZ conization for cervical intraepithelial neoplasia. In Vivo 2011; 25: 691-695

12 Boonlikit S, Yanaranop $M$. Thermal artifact after three techniques of loop excision of the transformation zone: a comparative study. Gynecol Obstet Invest 2012; 73: 230-235

13 Mossa MA, Carter PG, Abdu S et al. A comparative study of two methods of large loop excision of the transformation zone. BJOG 2005; 112: 490-494

14 Murta EF, Resende AV, Souza MA et al. Importance of surgical margins in conization for cervical intraepithelial neoplasia grade III. Arch Gynecol Obstet 1999; 263: 42-44

15 Kyrgiou M, Koliopoulos G, Martin-Hirsch P et al. Obstetric outcomes after conservative treatment for intraepithelial or early invasive cervical lesions: systematic review and meta-analysis. Lancet 2006; 367: 489-498

16 Kyrgiou M, Valasoulis G, Stasinou SM et al. Proportion of cervical excision for cervical intraepithelial neoplasia as a predictor of pregnancy outcomes. Int J Gyn Obstet 2015; 128: 141-147

17 Wright TC jr., Gagnon S, Richart RM et al. Treatment of cervical intraepithelial neoplasia using the loop electrosurgical excision procedure. Obstet Gynecol 1992; 79: 173-178

18 Krebs HB, Pastore L, Helmkamp BF. Loop electrosurgical excision procedures for cervical dysplasia: experience in a community hospital. Am J Obstet Gynecol 1993; 169: 289-293

19 Wright TC jr., Richart RM, Ferenczy A et al. Comparison of specimens removed by $\mathrm{CO} 2$ laser conization and the loop electrosurgical excision procedure. Obstet Gynecol 1992; 79: 147-153

20 Baggish MS, Barash F, Noel Y et al. Comparison of thermal injury zones in loop electrical and laser cervical excisional conization. Am J Obstet Gynecol 1992; 166: 545-548

21 Mathevet $P$, Dargent $D$, Roy $M$ et al. A randomized prospective study comparing three techniques of conization: cold knife, laser and LEEP. Gynecol Oncol 1994; 54: 175-179

22 Tseng CJ, Liang CC, Lin CT et al. A study of diagnostic failure of loop conization in microinvasive carcinoma of the cervix. Gynecol Oncol 1999; 73: 91-95

23 Luesley D, Leeson S. Colposcopy and Programme Management. Guidelines for the NHS Cervical Screening Programme. Sheffield, UK: NHS Cancer Screening Programmes Publication No 20; 2010

24 Papoutsis D, Panikkar J, Gornall A et al. Does the number of tissue fragments removed from the cervix with excisional treatment for CIN pathology affect the completeness of excision and cytology recurrence at follow-up? An observational cohort study. J Obstet Gynaecol 2016; 36: 251-256

25 Miroshnichenko GG, Parva M, Holtz DO et al. Interpretability of excisional biopsies of the cervix: cone biopsy and loop excision. J Low Genit Tract Dis 2009; 13: 10-12

26 Boardman LA, Steinhoff MM, Shackelton $R$ et al. A randomized trial of the Fischer cone biopsy excisor and loop electrosurgical excision procedure. Obstet Gynecol 2004; 104: 745-750 